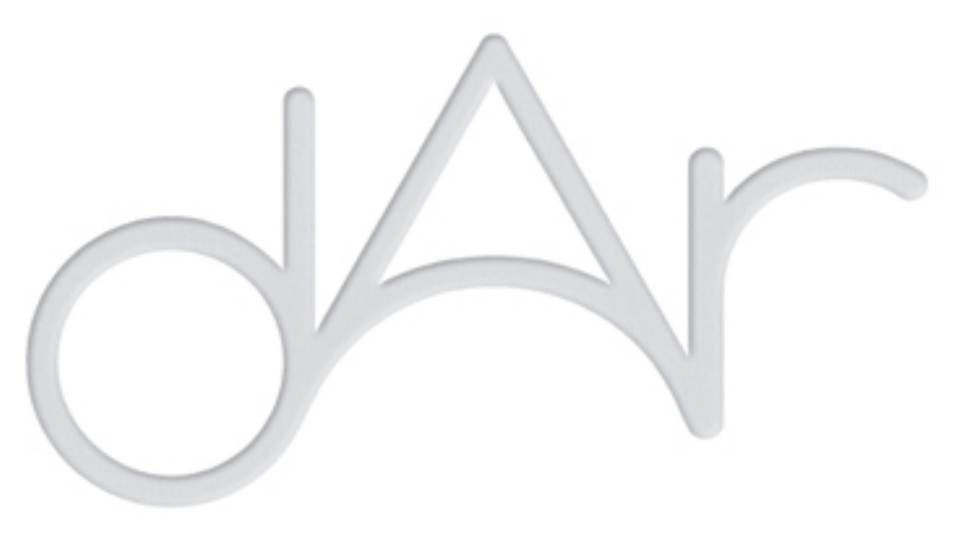

\title{
Patrimonio Industrial en Tierra Cruda: la Salitrera de María Elena, un Modelo Constructivo Mixto
}

\author{
Autor(es): $\quad$ Silva, Natalia Jorquera \\ Publicado por: CEAUCP \\ URL \\ persistente: URI:http://hdl.handle.net/10316.2/9121 \\ DOI: DOI: http://dx.doi.org/10.14195/2182-844X_1_3
}

Accessed : $\quad$ 26-Apr-2023 12:36:00

A navegação consulta e descarregamento dos títulos inseridos nas Bibliotecas Digitais UC Digitalis, UC Pombalina e UC Impactum, pressupõem a aceitação plena e sem reservas dos Termos e Condições de Uso destas Bibliotecas Digitais, disponíveis em https://digitalis.uc.pt/pt-pt/termos.

Conforme exposto nos referidos Termos e Condições de Uso, o descarregamento de títulos de acesso restrito requer uma licença válida de autorização devendo o utilizador aceder ao(s) documento(s) a partir de um endereço de IP da instituição detentora da supramencionada licença.

Ao utilizador é apenas permitido o descarregamento para uso pessoal, pelo que o emprego do(s) título(s) descarregado(s) para outro fim, designadamente comercial, carece de autorização do respetivo autor ou editor da obra.

Na medida em que todas as obras da UC Digitalis se encontram protegidas pelo Código do Direito de Autor e Direitos Conexos e demais legislação aplicável, toda a cópia, parcial ou total, deste documento, nos casos em que é legalmente admitida, deverá conter ou fazer-se acompanhar por este aviso.

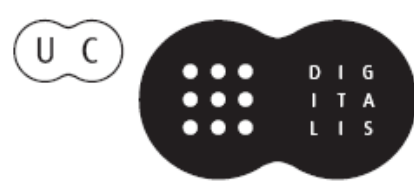


$6^{\circ}$ Seminário de Arquitectura em Terra em Portugal ( $6^{\circ}$ ATP) $9^{\circ}$ Seminário Ibero-americano de Construção e Arquitectura com Terra (9 SIACOT)

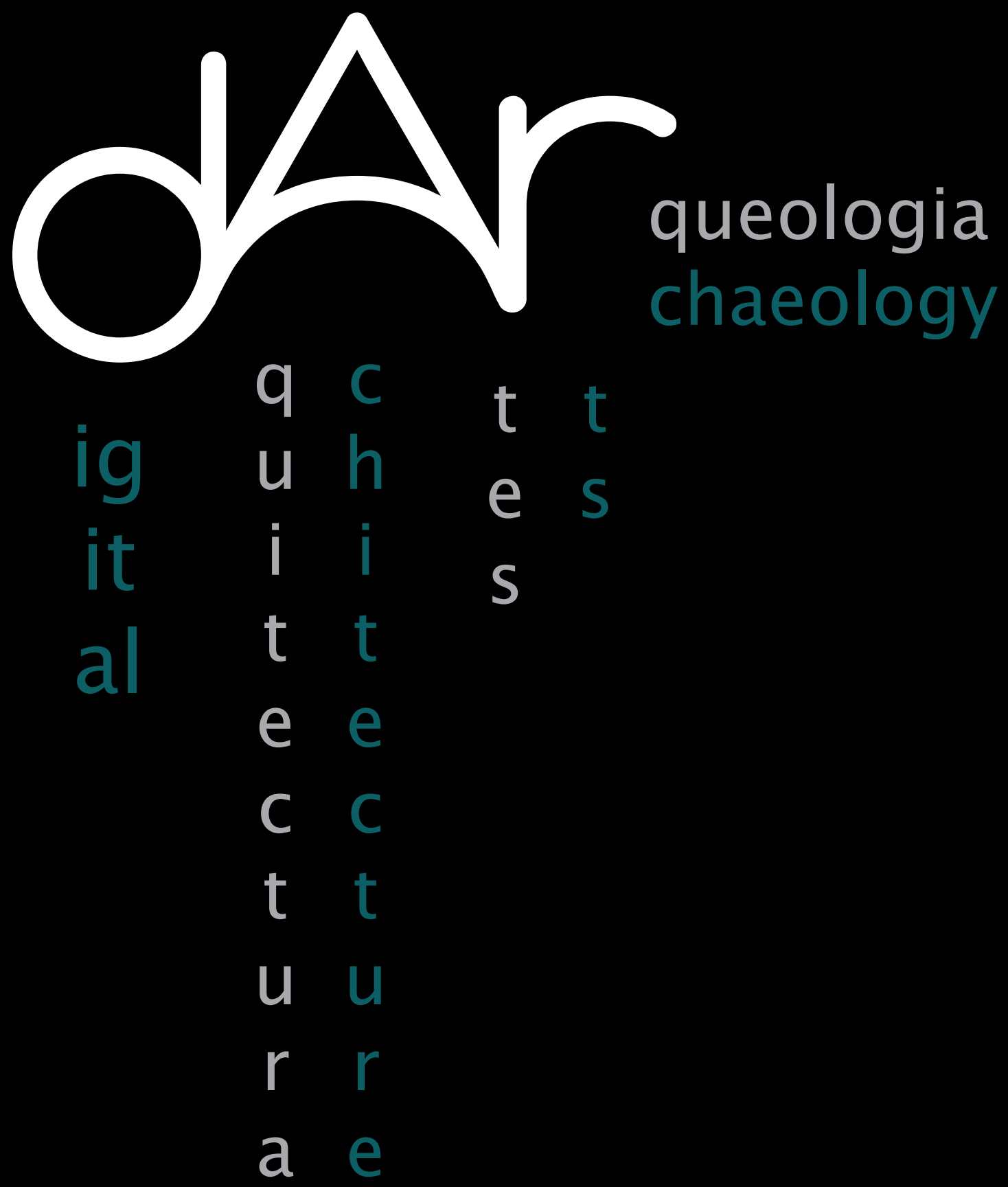




\title{
PATRIMONIO INDUSTRIAL EN TIERRA CRUDA: LA SALITRERA DE MARÍA ELENA, UN MODELO CONSTRUCTIVO MIXTO
}

\author{
Natalia Jorquera Silva* (Chile) \\ Dipartimento di Tecnologie dell'Architettura e Design "Pierluigi Spadolini" \\ Universitá di Firenze
}

\section{RESUMEN}

María Elena es una ciudad minera del norte de Chile construida en pleno desierto de Atacama a inicios del siglo XX; los edificios de su centro cívico constituyen una muestra patente de la fusión entre dos culturas constructivas: la industrial que tiene como principio la prefabricación y el uso del hierro, importada por los norteamericanos que fundaron la ciudad, y la arquitectura local basada en la utilización del adobe, que representa como material el mecanismo más eficaz de adaptación al hostil clima de la pampa. Este interesante sistema constructivo era desconocido hasta que en Noviembre del 2007, un fuerte terremoto afectara la zona y los daños presentes en los edificios dejaron entrever que bajo los gruesos muros de adobe, existían pilares de hierro o de madera.

El presente documento tiene como objetivo el profundizar la investigación sobre las tipologías arquitectónicas y los sistemas constructivos que componen dicho patrimonio industrial (1), a la vez que mostrar los proyectos de restauración de los Monumentos Históricos afectados por el sismo, llevados a cabo por la consultora chilena Surtierra Arquitectura.

Palabras clave: ciudad minera, patrimonio industrial en tierra, sistemas constructivos mixtos. 


\section{INTRODUCCIÓN}

La comuna de María Elena, ubicada en la región de Antofagasta, se encuentra emplazada en pleno desierto de Atacama, en lo que comúnmente se denomina "la pampa", una planicie en la depresión intermedia que constituye uno de los lugares más áridos del mundo; allí funciona una de las últimas mineras que extrae salitre (nitrato de sodio) en funcionamiento en el mundo, con un campamento minero asociado donde en la actualidad vive una población de 7 mil habitantes.

El territorio de la pampa atacameña desde épocas precolombinas ha sido rico en distintos tipos de minerales, transformándose la minería en una de las principales fuentes de desarrollo para Chile; a partir de la Guerra del Pacífico (1879-1884) el territorio se dedicó a la explotación del salitre hasta los años 30' y luego a la explotación del cobre a gran escala.

El salitre, extraído del llamado "caliche" (2) comienza a ser especialmente requerido desde Europa a partir de 1830, utilizado como abono y más tarde en la fabricación de explosivos; esta demanda llevó a la explotación del caliche en un vasto territorio que derivó en la creación de más de 55 oficinas salitreras, en poder preferentemente de peruanos y chilenos, dueños del mayor depósito natural de yodo y nitrato del mundo; a partir de la Guerra del Pacífico, Chile se anexa los territorios del desierto de Atacama y se transforma en el mayor productor de nitrato del mundo. Así, entre 1880 y 1930 las exportaciones salitreras constituyeron la principal área de la economía chilena, lo que se conocerá como el periodo del "auge del salitre".

Alemania que fue el principal comprador de salitre chileno, luego del bloqueo comercial que le es impuesto a partir de la Primera Guerra Mundial, inventa el salitre sintético, que lleva a la obsolescencia del proceso de extracción clásico conocido como Shanks y provoca el cierre de numerosas oficinas salitreras y el desempleo de miles de trabajadores; así en 1924 "The Lautaro Nitrate Company Limited" cerraba las puertas de la oficina Chacabuco, la última gran oficina con tecnología Shanks. Ante esta situación los inversores norteamericanos Guggenheim Brothers intentaron recuperar la competitividad de la industria con el desarrollo de un nuevo método de elaboración, denominado Sistema Guggenheim; este sistema pretendió hacer la competencia al salitre sintético, disminuyendo los costos de producción, gracias al ahorro de energía (lixiviación a menor temperatura), mayor mecanización del sistema y utilización de caliches de ley más baja. (Velasco, 2008, p.4)

En ese contexto, a partir de 1925 se inicia la construcción de "María Elena" la primera oficina salitrera en incorporar el nuevo método de extracción Guggenheim. El campamento minero, diseñado por ingenieros y arquitectos norteamericanos y construido por manos pampinas entre 1925 y 1927, se basó en el concepto de "ciudad ideal" para albergar a una ingente cantidad de trabajadores venidos de diversos lugares de Chile y de países limítrofes que se integraban a este nuevo impulso de la minería del salitre. La finalidad de este nuevo concepto era posibilitar que los mineros se identificaran con los espacios institucionales de la empresa Anglo-Chilean Consolidates Nitrate Corporation (dueña e impulsora de este proyecto), para que se arraigaran en ese contexto geográfico tan adverso como lo es la pampa en el desierto más árido del mundo. (Velasco, 2008, p.5)

El trazado de la ciudad posee forma de bandera inglesa, esto es, una planta octogonal, con cuatro lados mayores y cuatro lados menores, desde donde surgen dos diagonales que convergen en la plaza, entorno a la cual se ubican los edificios más importantes correspondiente a las instituciones públicas (Consejo de Monumentos Nacionales, 1999, p.1), y en las vías diagonales que se abrían desde allí, las viviendas para los mineros (ver Fig. 1). Los anchos de calles y la pequeña escala de las construcciones de un piso de habitación para los obreros traducen de cierta manera la vastedad del desierto que la rodea. 


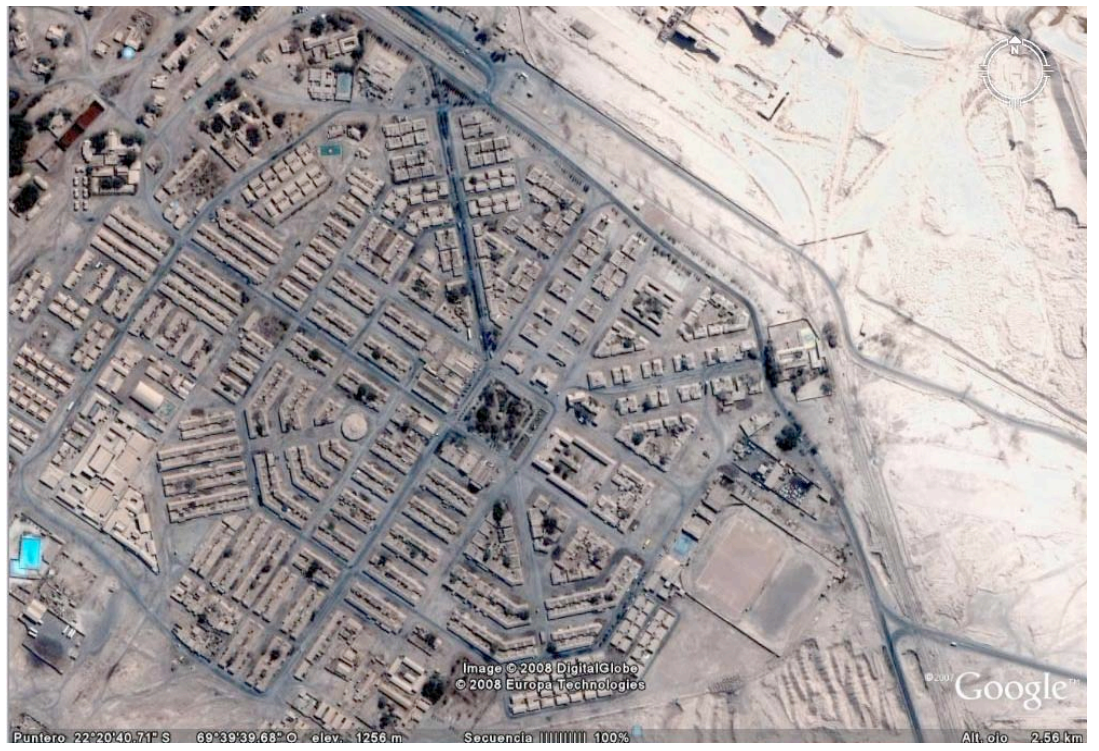

Fig. 1. Foto aérea donde se aprecia el trazado que hace alusión a la bandera inglesa. (Créditos: Surtierra Arquitectura, 2008; fuente: Google Earth)
Actualmente el territorio de María Elena y la totalidad de sus edificios pertenecen a la empresa privada SQM (Sociedad Química Minera), sin embargo por poseer una población superior a 6 mil habitantes, el Estado chileno cedió su administración a un Municipio; esta dualidad entre propiedad privada y administración pública ha llevado a más de una divergencia al momento de intervenir el espacio urbano y sus edificios, sobre todo luego del terremoto de Noviembre del 2007, cuando el Municipio frenó las labores de demolición llevadas a cabo por la empresa sobre un gran número de edificios dañados, y llamó a su restauración a través del Ministerio de Obras Públicas.

\section{LAS TIPOLOGÍAS ARQUITECTÓNICAS DE MARÍA ELENA Y EL USO DE LA TIERRA.}

La planificación de María Elena tuvo que lidiar con la hostilidad del contexto geográfico, creando un asentamiento artificial donde no existía ningún tipo de recursos naturales que permitiese satisfacer las necesidades básicas como el alimentar a la gran población obrera, así desde sus inicios tuvieron que pensarse rutas de abastecimiento de productos desde otras localidades, así como dotar al campamento de infraestructura acorde a los nuevos tiempos.

Como la mayoría de los campamentos salitreros, María Elena tuvo un diseño altamente estratificado y jerarquizado, donde la separación entre obreros y jefes se expresaba en barrios distintos, dividiéndose la ciudad en tres zonas bien diferenciadas: el centro donde se ubican los servicios, la zona residencial para los obreros a continuación del centro, y las casas de los gerentes de las minas en la periferia, más cerca de la planta de explotación minera.

En este contexto de aridez y aislamiento, la tierra se trasformó en el principal material de construcción para los distintos tipos de edificios al ser lo único que existe a mano como recurso local, dando lugar a diversas tipologías constructivas y modelos arquitectónicos. Cabe destacar que la tierra del lugar -el caliche- posee una baja presencia de arcilla y en cambio un gran porcentaje de sal, lo que en otro contexto hubiera resultado nefasto para la construcción de adobes, sin embargo, gracias a la invención de sistemas mixtos de construcción y a la casi nula pluviosidad de la zona, se pudieron construir edificios que hasta el día de hoy no poseen ningún tipo de degrado físico-químico a pesar de la calidad de dicha materia prima. Dentro de este esquema, resulta interesante que la tierra fue elegida para los edificios de alto nivel como las instituciones públicas y las viviendas de los gerentes de las minas -rompiendo el esquema de asociación del uso de la tierra con la pobreza-, debido a 
su capacidad de apaciguar las grandes fluctuaciones de temperatura que afecta a la zona desértica de Atacama, con mínimas de $-15^{\circ}$ y máximas sobre los $30^{\circ}$.

Así, los edificios del llamado centro cívico donde se encuentran agrupados todos los servicios, dada la gran envergadura que requerían, fueron construidos en un sistema mixto consistente en grandes estructuras metálicas o de madera, embebidas al como "New Mexico", consistente en fachadas de altura superior al resto del volumen, cuyas cornisas son decoradas con geometrías de curvas alargadas que esconden las aguas de la techumbre (ver Fig. 2); dicha decoración es también modelada en tierra.

Esta organización inicial de la ciudad, aún hoy se mantiene y está completamente vigente en todos sus usos, existiendo un

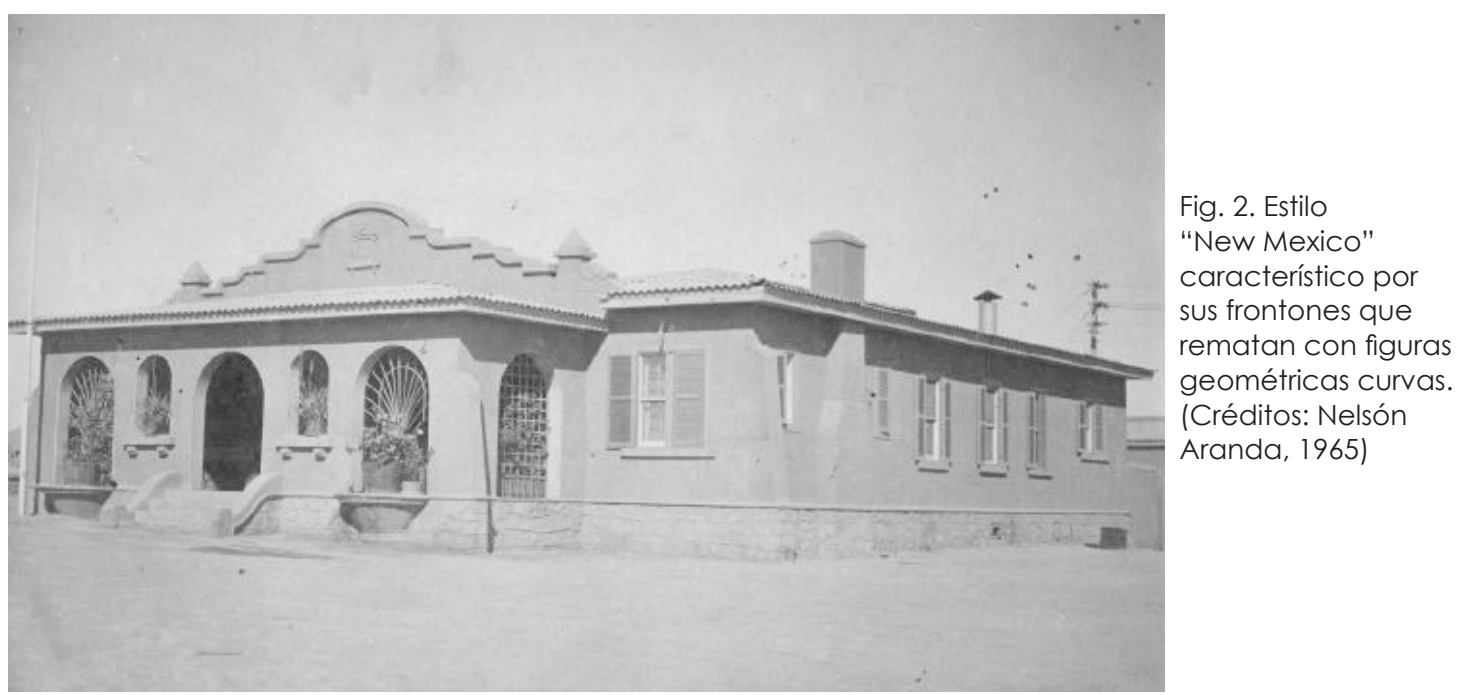

interior de gruesos muros de adobe, dando origen a especies de galpones de tierra, de grandes luces y alturas.

Los chalets de los gerentes ubicados en el llamado "barrio americano", eran de tipología aislada, sólo de un piso y utilizaron en su totalidad gruesos muros de adobe en dobles hiladas (60 cms. de espesor).

Las viviendas obreras por su parte, agrupadas en hileras de 12 casas pareadas con un pequeño patio trasero, por ser de menor calidad, fueron construidas en tabiquerías de madera, malla metálica y relleno de tierra con un pequeño porcentaje de cemento, una especie de quincha rellena con suelo-cemento, presentando una calidad térmica y acústica muy por debajo del resto de los edificios de la ciudad, al tener muros de espesores menores.

Un elemento en común de las tres tipologías mencionadas, es la adopción de un particular estilo arquitectónico conocido arraigo muy grande de la población minera al campamento donde la mayoría vive desde hace generaciones, creando vínculos muy profundos que ha llevado a la población al oponerse a dejar el territorio, pese a los intentos de la empresa privada SQM por cerrar el campamento y dejar allí en funcionamiento sólo la planta de extracción.

\section{LOS MONUMENTOS DEL BARRIO CÍVICO Y LOS SISTEMAS CONSTRUCTIVOS MIXTOS}

Los edificios institucionales de la ciudad, se encuentran ubicados entorno a la Plaza de Armas, en el punto donde convergen las avenidas principales, siendo desde un inicio, los referentes verticales en el vasto espacio horizontal de la pampa, tanto por sus dimensiones, altura, posición estratégica, como por encontrarse aislados en todas sus caras, y por ende con suficiente perspectiva y amplitud para ser observados. Todo el conjunto posee una gran unidad estilística y simbólica para la ciudad, lo que llevó a su declaratoria como un único Monumento 
Histórico denominado "Edificios del barrio cívico de las salitreras de María Elena" (3). Dichos Monumentos poseen además de los valores históricos asociados a la representatividad de una época de la Historia de Chile, el gran valor de ser fruto de la fusión entre dos culturas constructivas: la norteamericana, manifestada en la arquitectura industrial de gran escala, y la local, presente en la utilización del adobe, así, todos los Monumentos que conforman el barrio cívico comparten el estar construidos en sistemas mixtos que representan dicha fusión.

Los edificios fueron concebidos como grandes galpones de estructura metálica o madera (compuestos por pilares y cerchas) que salvan grandes luces en ambos sentidos, con una técnica y lenguaje propios de la arquitectura industrial que se usaba en Estados unidos y Europa en los años '20; dichas estructuras se encuentran recubiertas o "ahogadas" dentro de muros de adobe en dobles hiladas, por ende con espesores entorno a los 60 centímetros que esconden completamente las estructuras mencionadas; como elemento mediador, se presentan escalerillas metálicas de malla desplegada, puestas sistemáticamente cada tres hileras de adobe, que de este modo segmentan los muros en su altura, disminuyendo los posibles momentos volcantes y mejorando las tracciones frente a esfuerzos horizontales (ver Fig. 3). Todo este conjunto de decisiones fueron pensadas en la gestación de las obras, según lo demuestran los planos y especificaciones técnicas originales, y constituyen un sistema antisísmico altamente eficiente que ha permitido a los edificios responder exitosamente, manteniéndose en pie a pesar de los grandes sismos que han debido soportar desde su construcción a fines de los años 20 '; sin embargo cabe destacar que debido a la falta de información y a la apariencia de los edificios, éstos se encontraban catalogados como de "adobe simple" hasta el momento en el que se llamó a la restauración de ellos luego del sismo del 2007; fue sólo hasta la prospección de los mismos y a la recopilación de información histórica que se descubrió las estructuras embebidas, lo que constituyó un "hallazgo" constructivo-tecnológico-patrimonial.

En el costado norte de la plaza se ubican los edificios correspondientes al Banco del Estado y el Inchinor (primer Instituto Chileno Norteamericano de Chile), también
Fig. 3. Detalle sistema constructivo mixto adobe-metal. (Créditos: Surtierra Arquitectura, 2008)

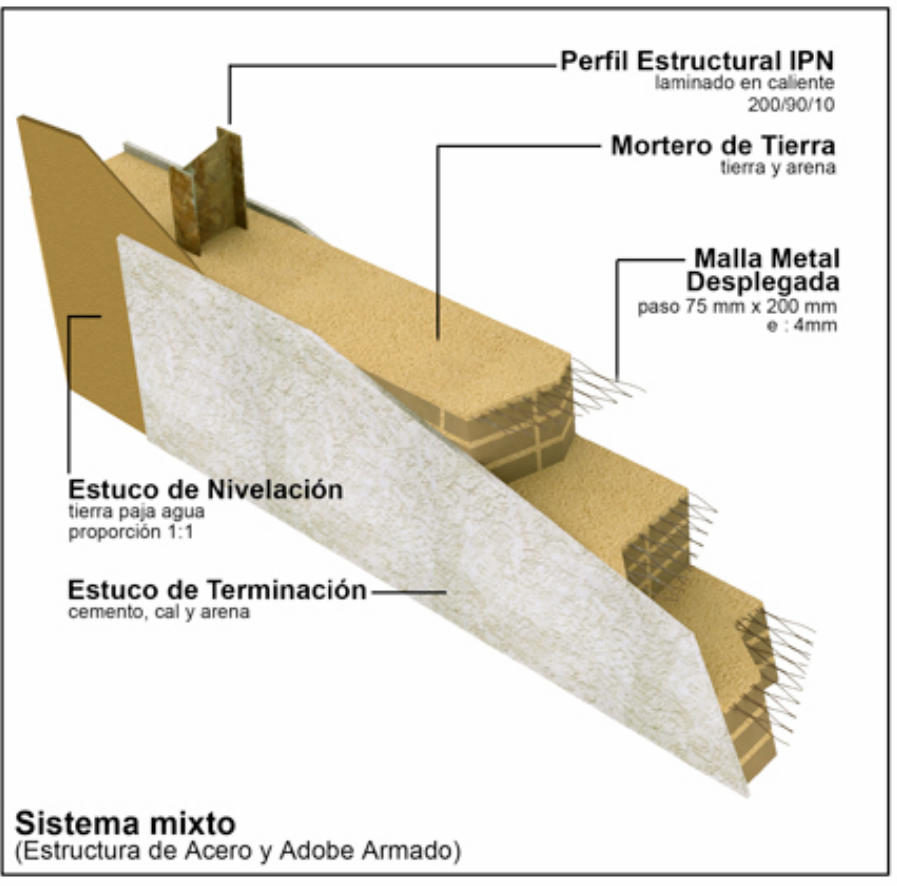


conocido como Ex Baños Públicos por el segundo uso que albergó, y en el nororiente, la Iglesia San Rafael Arcángel, todos inmuebles construidos en sistemas mixtos adobe-madera (pilares embebidos) y mallas metálicas.

En el lado oriente se encuentra la ex Escuela de la ciudad, llamada Escuela Consolidada, sin duda el edificio más emblemático por su escala, estilo, y por ocupar un entero frente (ver Fig. 4); ella se encuentra construida en sistema mixto adobe-hierro (en pilares y cerchas) y mallas metálicas.

En el lado sur, el Museo de la Ciudad, el Sindicato de trabajadores -ambos construidos en sistema mixto adobe-hierro- y el Teatro Metro, el único en estilo más bien Art Decó, y construido en una técnica mixta diferente, consistente en estructura metálica, hormigón armado en foyer y escenario, y doble tabiquería de madera revestida con malla desplegada y relleno de cemento y tierra (suelo cemento) en los muros laterales de la sala principal; este sistema representa otro momento constructivo por su data posterior al resto de los edificios (1948).

Por último, en el costado poniente de la plaza, se ubican el Mercado y la Pulpería de la ciudad, ambos edificios de grandes luces, construidos en sistema adobe-estructura metálica; la Pulpería lamentablemente

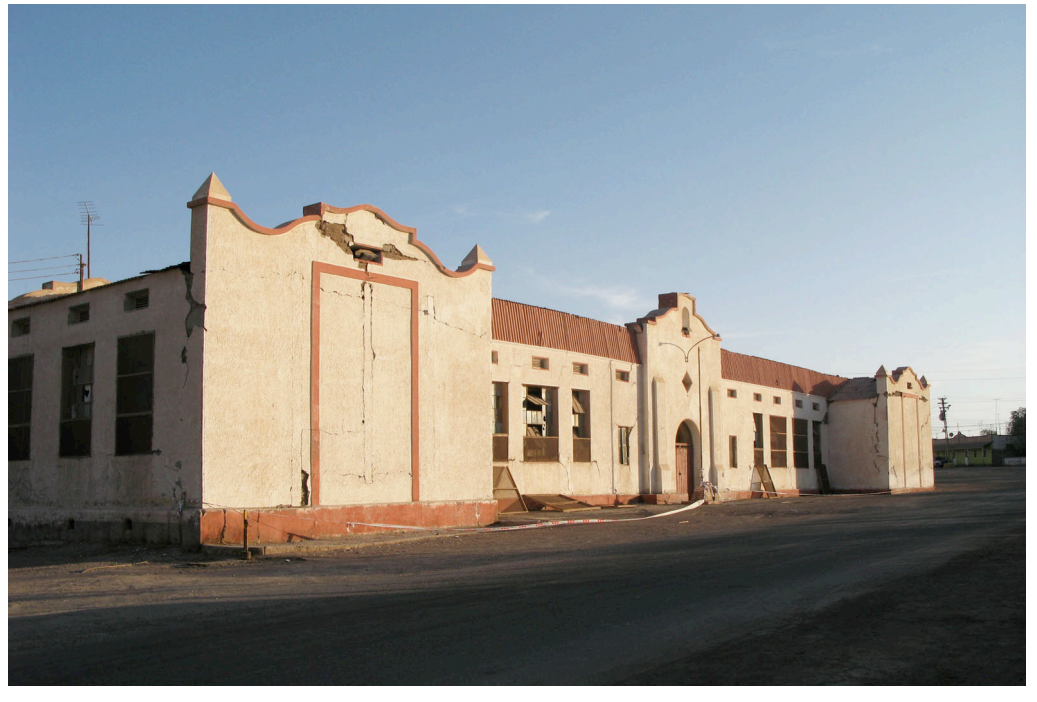

Fig. 4. La ex Escuela

Consolidada, el edificio más emblemático de María Elena. (Créditos: Surtierra Arquitectura, 2008)

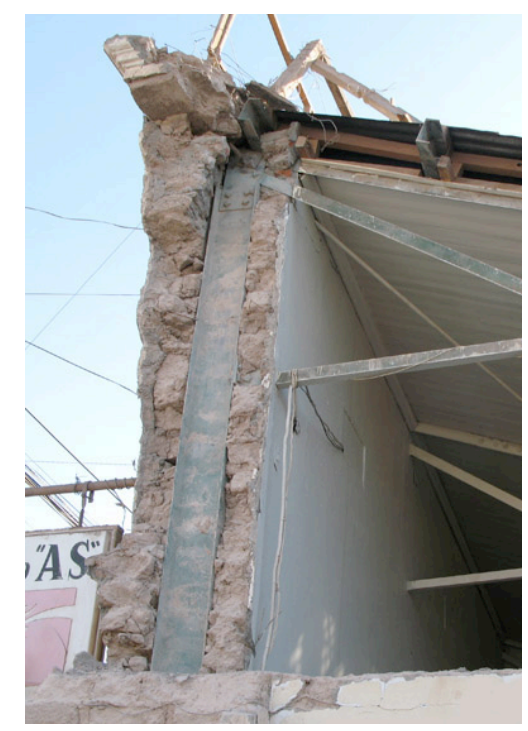

es de todos los edificios, el que más intervenciones presenta, lo que ha debilitado mucho su estructura y por tanto luego del sismo del 2007, se encuentra muy dañado (ver Fig. 5).

\section{LOS PROYECTOS DE RESTAURACIÓN}

El sismo del 14 de Noviembre del 2007, con epicentro en Tocopilla (Provincia a

Fig. 5. Parte de la Pulpería, donde la caída del tímpano permitió descubrir la presencia de la estructura de hierro embebida en los guesos muros de adobe. (Créditos: Surtierra Arquitectura, 2008) 
la cual pertenece María Elena), tuvo una intensidad de 7,7 grados en la escala sismológica de Richter y una duración de 1 minuto 35 segundos; fue percibido en gran parte de Chile, la región sur del Perú y algunos sectores de Bolivia, Argentina y Brasil (Karmelic, 2009, p.138) y tuvo efectos devastadores sobre las construcciones de gran parte del Norte Grande de Chile, donde incluso edificios nuevos construidos en hormigón armado, colapsaron. Las ciudades más afectadas fueron Tocopilla y María Elena, quedando más de 15 mil personas damnificadas y gran parte de las construcciones en el suelo; a raíz de ello, como medida de emergencia, el Consejo de Monumentos Nacionales declaró en enero del 2008 a toda María Elena Monumento Nacional en categoría de Zona Típica (4), con el fin de detener las posibles demoliciones y poder llamar a la restauración de los Monumentos, los cuales, cabe destacar, sufrieron graves daños, pero no colapsaron. A partir de dicha iniciativa se llamó a la realización de los proyectos de restauración de los Monumentos del barrio cívico, tarea que fue adjudicada a la consultora chilena Sur Tierra Arquitectura (5), dada su experiencia en restauración y estabilización sismo-resistente en inmuebles construidos con tierra cruda.

Los llamados a proyectos se dividieron en dos:

- Proyectos de restauración de los edificios Ex Escuela Consolidada, Iglesia San Rafael Arcángel, edificio Inchinor y Teatro Metro, encargado por la Dirección de Arquitectura del Ministerio de Obras Públicas regional de Antofagasta, con el fin de reparar, estabilizar estructuralmente y habilitar los inmuebles mencionados.

- Proyecto de "Diseño de apuntalamiento de emergencia" de los edificios Mercado y ex Pulpería, encargado por el Consejo de Monumentos Nacionales, como una medida de emergencia que permitiera seguir utilizando lo que es el núcleo comercial del barrio cívico; el proyecto contempló un diagnóstico estructural y un sistema de estabilización que evitara el colapso total o parcial de los edificios, disminuyendo el riesgo para la población, en espera de un futuro proyecto de restauración.

Dentro del proyecto de restauración, los 4 edificios requerían distintos niveles de intervención dependiendo su estado de conservación y uso. Así, el proyecto de restauración para la iglesia San Rafael Arcángel y el Teatro Metro, apuntó básicamente a la consolidación estructural y a la realización de intervenciones arquitectónicas puntuales (como la construcción de un nuevo altar y escenario respectivamente), pues ambos edificios se encontraban en general en buen estado de conservación (presentan daños puntuales) y mantenían su uso original.

En el caso del edificio Inchinor y la Ex Escuela Consolidada, las intervenciones fueron mayores, debido a la envergadura de sus daños estructurales y a que ambos se encontraban en desuso y en espera de albergar una nueva función. Para ambos, se contempló como primera medida la consolidación estructural, operaciones de restauración tales como liberaciones e integraciones y la asignación de un nuevo programa arquitectónico: para Inchinor, se proyectó la habilitación de una Biblioteca Pública, y para la Ex Escuela, un Museo de María Elena, que albergara la muestra total del actual Museo de la comuna, además de las oficinas de Cultura y Turismo de la Municipalidad y otras asociaciones deportivas y culturales de la comuna; dichos usos fueron elegidos por la llustre Municipalidad de María Elena.

En el caso del Mercado de María Elena y la ex Pulpería, los proyectos se basaron en el diagnóstico exhaustivo de los daños de origen sísmico y en soluciones puntuales para ellos que pudieran ser reversibles hasta el momento de la restauración integral. El Mercado conserva su arquitectura original y prácticamente no ha sufrido modificaciones por lo que se encuentra en buen estado de conservación, a pesar de los eventos sísmicos. El caso de la ex Pulpería en cambio, es distinto, ya que ha sufrido muchas intervenciones en el tiempo, en 
sistemas estructurales distintos, no siempre compatibles con la obra original, por lo que se encuentra severamente dañado; ambos edificios se encuentran en uso y constituyen el corazón comercial de María Elena.

Todos los proyectos partieron con la visita a terreno de la consultora y la prospección de los daños, a raíz de la cual se descubrieron los sistemas constructivos mixtos antes descritos; en dicha visita se constató que se presentaban muy pocos vaciamientos o desaplomes y que en los casos donde existían, habían sido provocados por asentamientos diferenciales debidos a la pérdida de estabilidad del suelo por la disolución de las sales presentes en la tierra, causa de la mala mantención de las redes de agua y alcantarillado que ocasionaban filtraciones, siendo éste un factor externo que produjo que los edificios concentraran sus mayores daños entorno a las zonas húmedas y no una causa intrínseca atribuida al sistema constructivo; en las partes donde no se presentaban filtraciones en cambio, los daños fueron menores, y consistían principalmente en grietas en los encuentros de muros, y entre éstos y la estructura de pilares metálicos, lo que luego de las prospecciones demostró deberse a falta de continuidades producto de que las escalerillas metálicas presentes cada tres hiladas de adobe, no se encontraban amarradas entre ellas en las esquinas, ni tampoco a las estructuras metálicas o de madera.

Debido a la importancia de tales indagaciones, es que la parte inicial de los proyectos estuvo destinada a la comprensión y levantamiento tecnológico de cada una de las partes constructivas de los edificios, con el fin de proponer soluciones compatibles con dichos sistemas, estableciendo como principales criterios de intervención el aislar las zonas húmedas y el dar continuidad estructural a los edificios; estos criterios fueron utilizados para los 6 Monumentos ya que todos presentaban las mismas características iniciales; las medidas adoptadas fueron:

- Creación de una franja perimetral de suelo estabilizado entorno a los edificios, para reemplazar el suelo salino y alejar el agua.

- Creación de amarre entre los distintos componentes a través de la incorporación de mallas electrosoldada tipo Acma, ubicadas de manera vertical en los encuentros de muros perpendiculares (generando trabazones entre ambos elementos) y en zonas propensas a vaciamientos. Dichas mallas fueron amarradas a las escalerillas metálicas existentes.

- Creación de un collar superior de amarre sobre todo el edificio para otorgar continuidad estructural.

En el caso del Mercado y la Pulpería, las labores de "amarre" estructural se remitieron a la zona de los daños a través de la incorporación de "parches" confeccionados con mallas metálicas verticales (paralelas al paramento) que iban amarradas a las escalerillas metálicas existentes a través de nudos hechos con alambre, que permitieran la reversibilidad de la intervención (ver Fig. 6).

Se puede decir en resumen que los 6 proyectos tuvieron como principio la "máxima comprensión para una mínima intervención", en tanto que el estudio profundo de los sistemas constructivos de los edificios y su eficiencia demostrada permitió crear soluciones puntuales, proponiendo modelos de consolidación estructural "colaborantes" a lo ya existente.

\section{ALCANCES Y RELEVANCIA INTERNACIONAL DE LOS PROYECTOS}

La relevancia de María Elena como ejemplo de intervención patrimonial, trasciende a los proyectos de restauración antes descritos y amerita el continuar la investigación sobre el comportamiento de los sistemas constructivos mixtos que conforman los edificios, los cuales pueden tomarse como ejemplo para futuras propuestas de intervención del patrimonio construido en tierra en zonas sísmicas.

Según el Inventario del Patrimonio Cultural 

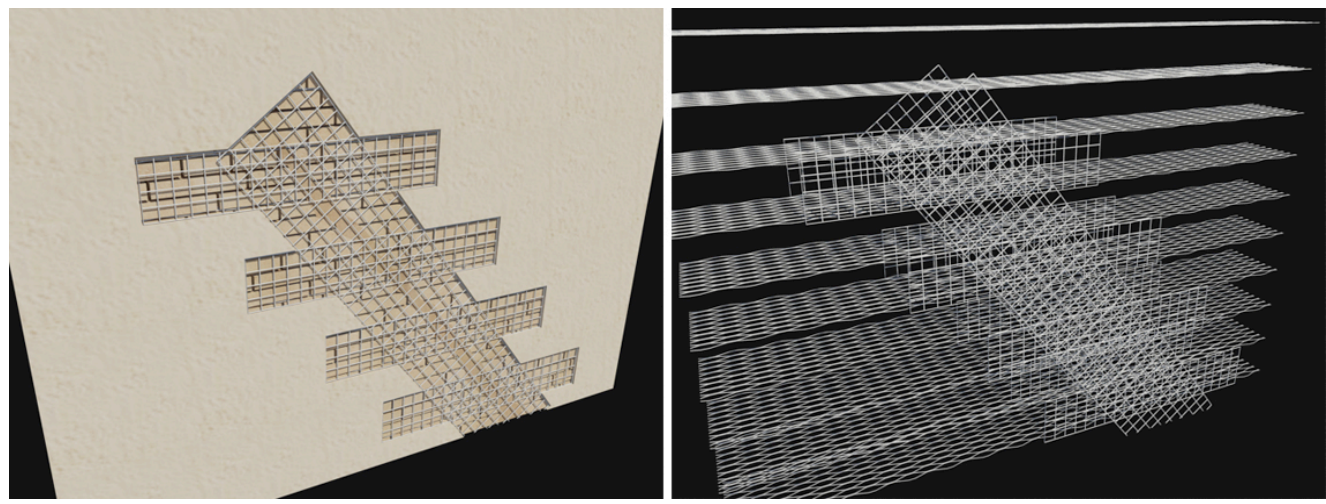

Fig. 6. Detalle de los "parches" de malla Acma y su amarre a las escalerillas de malla metálica desplegada existente, como estrategia de consolidación. (Créditos: Surtierra Arquitectura, 2008)

Inmueble en Chile, entorno al $40 \%$ del patrimonio arquitectónico se encuentra construido en tierra cruda (Karmelic, 2009, p.213), del cual gran parte se encuentra en estado vulnerable; a nivel mundial, existen aproximadamente unos 70 Monumentos de la Lista de Patrimonio Mundial construidos en tierra, de los cuales, el $57 \%$ de los mismos ha sido catalogado como parte de la Lista de Patrimonio Mundial en peligro por su actual estado de deterioro. Teniendo en cuenta estas cifras y el hecho de que todos los Monumentos de María Elena se encuentren hoy en pie, se hace necesaria la profundización de la investigación como un posible modelo de construcciones sismoresistentes construidas con tierra cruda a estudiar, a la vez que una ocasión para la discusión sobre las escazas normativas vigentes a nivel nacional e internacional sobre el uso de la tierra cruda en la edificación.

\section{Bibliografía}

Consejo de Monumentos Nacionales (1999). Edificios que conforman el barrio cívico de la oficina salitrera María Elena. Santiago, Chile: Ficha del Monumento del Consejo de Monumentos Nacionales. Consultada: 15/01/2008 en http://www.monumentos.cl.

Conti, V. (2006). La ruta de los arrieros y el salitre. Las rutas del Capricornio Andino. Huellas milenarias de Antofagasta, San Pedro de Atacama, Jujuy y Salta. Santiago, Chile: Cuadernos del Consejo de Monumentos Nacionales, 95-103.

Dirección de Arquitectura Ministerio de Obras Públicas (2008). Programa Puesta en Valor del Patrimonio. Consultada: 15/03/2009 en http:// www.arquitecturamop.cl/portada/0905

Garcés, E. (1999). Las ciudades del salitre. Santiago, Chile: Editorial Orígenes.

Karmelic, L. (2009). Estudio descriptivo de los inmuebles patrimoniales construidos en tierra cruda que forman parte del Inventario de Patrimonio Cultural Inmueble de Chile. (Santiago, Chile: proyecto de investigación para la obtención del Diploma de Estudios Avanzados, $2^{\circ}$ Versión Doctorado Arquitectura y Patrimonio Cultural - Ambiental Universidad De Sevilla y Universidad Central).

Surtierra Arquitectura (2008). Estudio de la situación original y actual de 4 Monumentos Históricos del Centro Cívico de María Elena. Antofagasta, Chile: Documentos de la Dirección de Arquitectura del Ministerio de Obras Públicas.

Velasco, H. (2008). Estudio antropológico María Elena y edificios Monumentos Históricos. Antofagasta, Chile: Documentos de la Dirección de Arquitectura del Ministerio de Obras Públicas.

Notas

(1) La presentación preliminar de los proyectos de restauración de los Monumentos de María Elena, fue presentada en el VIII Siacot de Tucumán por el arquitecto Marcelo Cortés. El equipo que desarrolló dichos proyectos fueron los arquitectos Patricio Arias, Pablo Alvear, Francisca Gómez, Sergio Briceño y la autora, todos miembros de la consultora Surtierra.

(2) El caliche es una masa compuesta de nitrato de sodio mezclado con otras sales como cloruros y sulfatos y otras substancias terrosas.

(3) Los edificios que se incluyen en la declaratoria "Edificios que conforman el barrio cívico de la 
oficina salitrera María Elena" con decreto 400 del 22/1 1/1999 son: la Ex Escuela Consolidada, la Ex Pulpería, Mercado, Teatro Metro, Iglesia San Rafael Arcángel, Sindicato № 3, Ex Baños Públicos (Inchinor), Banco del Estado, Asociación Social y Deportiva.

(4) En Chile los Monumentos Nacionales son protegidos a través de la Ley 17.288, siendo el Consejo de Monumentos Nacionales el organismo responsable de pronunciarse sobre la conveniencia de declarar dicha nominación y solicitar a la autoridad competente -el Ministro de Educación- la dictación del decreto supremo de protección. Existen 5 categorías de Monumentos Nacionales: Monumento Histórico, Monumento Público, Monumento Arqueológico, Zona Típica, Santuario de la Naturaleza.

(5) La consultora chilena Surtierra Arquitectura, compuesta por los socios arquitectos Marcelo Cortés y Patricio Arias, desarrolla proyectos de arquitectura contemporánea y construcción con tierra cruda, así como restauración de inmuebles construidos en tierra 